\title{
Editorial
}

\section{Efectos de la reactivación económica en Colombia}

$\mathrm{L}$ a crisis económica que afronta Colombia por cuenta de la pandemia del coronavirus es de proporciones gigantescas. Las expectativas de reactivación de los distintos sectores económicos son crecientes. Si bien es cierto que se observó un repunte en mayo en comparación con el mes de abril, las estadísticas divulgadas por el Departamento Nacional de Estadística (DANE) para el primer semestre del año en curso son dramáticas. El DANE pronostica que la producción al finalizar el 2020 descenderá un $10 \%$ y el empleo, un $20 \%$.

El proceso de reapertura de los sectores que aún no han empezado está condicionado a que el número de contagiados del coronavirus, ligado a la demanda de infraestructura hospitalaria para atender a los pacientes afectados, descienda. A pesar de ello, es determinante que las autoridades económicas diseñen una estrategia de reactivación con el fin de recuperar gradualmente la actividad económica.

A propósito, en la instalación del Congreso de la República, el 20 de julio, el presidente Duque, al anunciar el programa de reactivación Nuevo Compromiso por el Futuro de Colombia, planteó "que contará con una inversión de alrededor de 100 billones de pesos, para crear un millón de empleos e impulsar el crecimiento de nuestro país. Dentro de él, nos trazamos cuatro objetivos fundamentales, como son el apoyo a los más vulnerables, el crecimiento limpio, la generación de empleo y un gran compromiso con el campo y la paz con legalidad". Pese a que los cuatro objetivos son loables, habrá que esperar que se puedan alcanzar. Si se hace referencia a los dos últimos, es necesario tener en cuenta los programas y proyectos que se están ejecutando y aquellos que hasta ahora se comienzan a diseñar.

Sin duda, dada la situación laboral del país, la creación de nuevos puestos de trabajo dentro de un proceso de reactivación es una necesidad sentida, comoquiera que la tasa de desempleo en junio fue de $19.8 \%$. Por otra parte, varios sectores, como el comercio, los servicios, la infraestructura, la construcción de vivienda, entre otros, están en posibilidades de contribuir con dicho objetivo, aunque solo los dos últimos volvieron a funcionar desde mediados de mayo. 
En el caso de la infraestructura es considerable su potencial en la generación de empleo y el dinamismo que puede transmitir a otros sectores. En este sector hay proyectos que ya venían ejecutándose antes de la pandemia y otros que apenas están iniciándose.

La infraestructura vial y de transporte es deficiente e insuficiente, por lo que mejorarla sería una forma de contribuir tanto a la competitividad como a la productividad del país. Es necesario que los proyectos viales avancen; además, se espera que en este período presidencial culminen los programas de vías de cuarta generación, en operación desde la administración de Juan Manuel Santos.

También está en marcha el programa de vías $5 \mathrm{G}$, que incluye 28 proyectos cuya financiación asciende, aproximadamente, a 53 billones de pesos. En este programa se incluyen varias obras, siendo las más destacadas los corredores de comercio exterior. Y se espera que se fortalezca el transporte intermodal con los proyectos que se ejecutan en el rio Magdalena. Simultáneamente, se busca restablecer el sistema férreo y adecuar algunos aeropuertos regionales en alianza con el sector privado. Desde luego que en este apartado también es urgente ampliar y modernizar la capacidad operativa de los puertos colombianos.

Así mismo, es importante tener en cuenta los proyectos que emprenderán diversas ciudades capitales colombianas, como es el caso de Bogotá con el metro y otras obras en las que el Distrito Capital ha proyectado inversiones cuantiosas para los próximos cuatro años y cuyo presupuesto asciende a cerca de 41 billones de pesos.

Por otro lado, en la reactivación económica y en la creación de empleo es clave el sector de la construcción de vivienda, pues es un sector que impulsa otras actividades, ya que genera una creciente demanda de otros sectores económicos; aún más, dado el déficit habitacional, constituye una fuente de alto potencial de crecimiento. Este sector presentaba unos indicadores preocupantes antes de la aparición de la pandemia, pero, posteriormente, por la reapertura de la construcción se redujo el efecto, particularmente en la construcción de vivienda de interés social, más que en la construcción de vivienda de otro destino. En conjunto, para el primer semestre del presente año las licencias para construir nuevas viviendas se redujeron en un $28 \%$. En suma, a pesar de los estímulos otorgados por el Gobierno a la construcción de vivienda, el sector se encuentra estancado y es posible que con la hipoteca inversa anunciada se desestimule aún más la construcción.

Otro sector que la administración Duque considera determinante para la reactivación es la producción agropecuaria, a pesar de que el PIB del mismo (agricultura, ganadería, caza, silvicultura y pesca) se redujo en el 2019, en comparación con el año 2000: 
disminuyó de $8.27 \%$, en el primer año, a $6.74 \%$ en el último año. Esta pérdida de participación no solo es una característica de la economía colombiana, sino que se observa en el mundo por el crecimiento de otras actividades, en especial del sector terciario de la economía.

Dentro de las acciones por emprender en el sector rural, el presidente Duque manifestó que estimulará el catastro multipropósito, los programas de desarrollo con enfoque territorial, la provisión de bienes públicos, entre otros programas. Indudablemente, este último sector es el que más rápido puede reactivar la economía y de esta forma contribuir al desarrollo agrícola. Las limitaciones de la infraestructura rural se presentan en todos los ámbitos: en materia vial, las deficiencias y carencias son enormes; por ello, la construcción de vías terciarias es una forma de facilitarles a los campesinos el transporte tanto de insumos como de productos agrícolas, además son intensivas en la creación de empleo. También es importante destacar la construcción de distritos de riego y la ampliación y el mejoramiento de la conectividad digital para acrecentar la productividad del sector, aparte de las construcciones escolares y hospitalarias, determinantes para elevar el bienestar de la población rural.

Por otro lado, igualmente en el sector rural, la administración Duque no le ha prestado atención a uno de los aspectos más álgidos de la reforma rural integral, como es el uso y tenencia de la tierra, con políticas conducentes a un uso adecuado de la misma y con el impulso a la formalización, la restitución y la distribución equitativa, tal como se estableció en el acuerdo de paz firmado entre el Estado colombiano y las desmovilizadas Fuerza Armadas Revolucionarias de Colombia (FARC).

Sin duda, la reactivación económica es una necesidad imperiosa, y los programas y proyectos, tanto en ejecución como aquellos que se espera impulsar, pueden contribuir a dinamizar la economía. Sin embargo, según informó la Contraloría General, en muchos de ellos, sobre todo en los de infraestructura vial ya iniciados, el avance es nulo y en otros es muy bajo, tal como se registra en el trayecto Mulaló-Loboguerrero, Santander de Quilichao-Popayán, y en el tercer carril del trayecto Bogotá-Girardot, entre otros. La explicación de tal situación, particularmente en las obras de infraestructura, se relaciona con el incumplimiento de los contratistas, la falta de adquisición de predios, el no acatamiento de los requisitos ambientales y sociales, entre otros.

Luis Eudoro Vallejo Zamudio

Director de la Revista Apuntes del Cenes

Como citar:

Vallejo Zamudio, L. (2020). Efectos de la reactivación económica en Colombia. Apuntes Del Cenes, 39(70). Págs. - 13 https://doi.org/10.19053/01203053.v39.n69.2020.10738 